\title{
Does use of a right internal thoracic artery increase deep wound infection and risk after previous use of a left internal thoracic artery?
}

Lars G. Svensson, MD, PhD, ${ }^{a}$ Mubashir A. Mumtaz, MD, ${ }^{a}$ Eugene H. Blackstone, MD, ${ }^{a, b}$ Jingyuan Feng, MS, ${ }^{b}$ Michael K. Banbury, MD, ${ }^{a}$ Joseph F. Sabik III, MD, ${ }^{a}$ B. Gosta Pettersson, MD, PhD, ${ }^{a}$ Steven M. Gordon, MD, and Bruce W. Lytle, MDa

From the Departments of Thoracic and Cardiovascular Surgery, ${ }^{a}$ Quantitative Health Sciences, ${ }^{\mathrm{b}}$ and Infectious Disease, ${ }^{\mathrm{c}}$ The Cleveland Clinic Foundation, Cleveland, Ohio.

Received for publication July 29, 2005; revisions received Sept 19, 2005; accepted for publication Sept 28, 2005.

Address for reprints: Lars G. Svensson, $\mathrm{MD}, \mathrm{PhD}$, The Cleveland Clinic Foundation, 9500 Euclid Ave/Desk F24, Cleveland, OH 44195 (E-mail: svenss1@ccf.org).

J Thorac Cardiovasc Surg 2006;131:609-13

$0022-5223 / \$ 32.00$

Copyright (C) 2006 by The American Association for Thoracic Surgery

doi:10.1016/j.jtcvs.2005.09.055
Objective: To determine whether adding right internal thoracic artery to previous left internal thoracic artery bypass at reoperation increases deep sternal wound infection and hospital mortality, particularly in diabetic patients.

Methods: Reoperations ( $\mathrm{n}=2875 ; 2381$ men) in patients with previous left internal thoracic artery bypass were performed between January 1990 and January 2003; $1939(67 \%)$ had no repeat internal thoracic artery grafting, $923(32 \%)$ received an additional right internal thoracic artery graft, and $13(0.5 \%)$ had bilateral internal thoracic artery grafting with reuse of the left internal thoracic artery. Of the patients, $352(12 \%)$ were insulin-treated and 590 (21\%) non-insulin-treated diabetics. Multivariable logistic regression analysis was used to identify preoperative variables associated with right versus non-right internal thoracic artery use in diabetics and nondiabetics and to formulate propensity models. Propensity scores were used for matching and adjusted multivariable analyses of deep wound infection and hospital mortality.

Results: Deep wound infection occurred in $3.0 \%$ (7/230) of diabetics receiving right internal thoracic artery grafts, $2.2 \%(5 / 230)$ of propensity-matched diabetics receiving non-right internal thoracic artery grafts $(P=.6)$, in $1.1 \%(6 / 538)$ of nondiabetics receiving right internal thoracic artery grafts, and in $1.0 \%(5 / 538)$ of matched non-diabetic patients receiving non-right internal thoracic artery grafts $(P=.8)$. Corresponding hospital mortality in these matched groups was $1.7 \%(4 / 230)$ versus $6.1 \%(14 / 230)$ for diabetics $(P=.02)$ and $2.6 \%(14 / 538)$ versus $3.5 \%(19 / 538)$ for nondiabetics $(P=.4)$. Risk factors for deep wound infection included higher weight $(P=.0003)$, higher New York Heart Association functional class $(P=.03)$, and less severe left anterior descending disease $(P=.03)$. Risk factors for death were $(P<.02)$ emergency operation, mitral valve replacement, and greater number of saphenous vein grafts.

Conclusions: Use of the right internal thoracic artery for reoperations does not increase the risk of deep wound infections in diabetics or nondiabetics and does not increase mortality.

$\mathrm{U}$ se of the left internal thoracic artery (LITA) for coronary artery bypass is safe and associated with improved long-term survival compared with saphenous vein grafting. Bilateral internal thoracic artery (ITA) grafting is associated with an even greater survival advantage. ${ }^{1-3}$ However, it has been shown to increase the risk of wound infection in some patients, particularly those with diabetes. ${ }^{4-19}$ We sought to determine whether patients who received a LITA graft at their first operation were at increased risk of deep wound infection when the right 


\author{
Abbreviations and Acronyms \\ $\mathrm{CL}=$ confidence limits \\ DWI $=$ deep wound infection \\ ITA $=$ internal thoracic artery \\ LAD $=$ left anterior descending coronary artery \\ LITA $=$ left internal thoracic artery \\ RITA $=$ right internal thoracic artery
}

internal thoracic artery (RITA) was used for the second operation, a staged use of bilateral ITAs.

\section{Patients and Methods}

Using the Cardiovascular Information Registry, we identified reoperations performed at The Cleveland Clinic Foundation between January 1990 and January 2003 on 2875 patients who previously had received a LITA graft. This registry has been approved for use in research by the Institutional Review Board. Average age was $66 \pm 9.2$ years, average weight was $83 \pm 15 \mathrm{~kg}$, and 2381 patients $(83 \%)$ were men. One thousand nine hundred thirty-nine $(67 \%)$ had no repeat ITA grafting, $923(32 \%)$ received an additional RITA, and $13(0.5 \%)$ had bilateral ITA grafting because the LITA could be used again.

Three hundred fifty-two patients $(12 \%)$ had insulin-treated diabetes and 590 (21\%), non-insulin-treated diabetes. Diabetes status could not be ascertained for 19 patients $(0.7 \%)$. Thus, analysis evaluating the influence of diabetes involved 2856 patients.

Q wave infarction was present in 885 patients (31\%), $68(2.4 \%)$ underwent emergency operation, and $42(1.8 \%)$ had endocarditis. Aortic valve replacement was performed in 471 (16\%), mitral valve repair in $275(9.6 \%)$, and mitral valve replacement in 121 (4.2\%). Patent LITAs were dissected out and clamped during reoperations, with retrograde blood cardioplegia relied on to protect the territory. In patients undergoing only mitral valve, aortic valve, or aortic surgery, particularly with deep hypothermia, the LITA was not necessarily isolated and clamped only if a rightsided bypass was needed. Average aortic clamp time was $90 \pm 32$ minutes, and average cardiopulmonary bypass time was $130 \pm 47$ minutes. Patients received cefuroxime as a prophylactic antimicrobial, except high-risk patients, who were given vancomycin.

Deep wound infection (DWI) was defined as in the Society of Thoracic Surgeons database: a sternal wound infection requiring operative intervention and excision of muscle, bone, or mediastinal tissue associated with positive wound cultures or treatment with antibiotics or antimicrobials. Superficial wound infections were not compared.

Intraoperative and postoperative blood glucose management evolved over time as its importance was increasingly recognized. ${ }^{13,14}$ Currently, all glucose levels above $150 \mathrm{mg} \cdot \mathrm{dL}^{-1}$ are treated with intravenous insulin. Similarly, during this period, skeletonization of ITAs was increasingly used, particularly for the RITA to obtain greater length to bypass distal right coronary territory arteries. ${ }^{8,18}$ For the past 2 years, vacuum dressings have been used for DWI.

\section{Data Analysis}

Multivariable logistic regression analysis was used to identify preoperative variables associated with RITA versus non-RITA use in diabetics and nondiabetics. These were amplified with nonstatistically significant variables to develop propensity models for fair comparison of RITA and non-RITA patients. ${ }^{20,21}$ Four propensity scores were calculated for each patient:

1. RITA versus non-RITA use in diabetics

2. RITA versus non-RITA use in nondiabetics

3. Diabetics versus nondiabetics receiving RITA grafts

4. Diabetics versus nondiabetics not receiving RITA grafts

Comparison of DWI and hospital mortality was made between propensity-matched groups. In addition, risk factors were identified for DWI and hospital mortality using bagging (250 bootstrap data sets with a retention criterion of $P \leq .05) .{ }^{22}$ Final risk factor models were adjusted by the propensity scores. ${ }^{23}$

\section{Presentation}

Continuous variables are summarized by means and 1 standard deviation. Categorical variables are summarized as frequencies

TABLE 1. Deep wound infection in nondiabetic and diabetic patients who did or did not receive RITA grafts at reoperation*

\begin{tabular}{|c|c|c|c|c|c|c|c|c|}
\hline \multirow{3}{*}{$\begin{array}{l}\text { RITA grafting } \\
\text { at reoperation }\end{array}$} & \multicolumn{4}{|c|}{ Nondiabetics } & \multicolumn{4}{|c|}{ Diabetics } \\
\hline & \multirow[b]{2}{*}{$\mathbf{n}$} & \multicolumn{3}{|c|}{ DWI } & \multirow[b]{2}{*}{$\mathbf{n}$} & \multicolumn{3}{|c|}{ DWI } \\
\hline & & No. & $\%$ & CL (\%) & & No. & $\%$ & CL (\%) \\
\hline \multicolumn{9}{|c|}{ Unmatched patients } \\
\hline Yes & 623 & 6 & 0.96 & $0.6-1.4$ & 271 & 9 & 3.32 & $2.3-4.8$ \\
\hline No & 1287 & 9 & 0.70 & $0.5-0.9$ & 675 & 11 & 1.63 & $1.2-2.3$ \\
\hline$P$ & .5 & & & & . & & & \\
\hline Total & 1910 & 15 & 0.79 & & 946 & 20 & 2.1 & \\
\hline \multicolumn{9}{|c|}{ Matched patients } \\
\hline Yes & 538 & 6 & 1.12 & $0.7-1.8$ & 230 & 7 & 3.04 & $1.9-4.6$ \\
\hline No & 538 & 5 & 0.93 & $0.5-1.6$ & 230 & 5 & 2.17 & $1.2-3.6$ \\
\hline$P$ & .8 & & & & . & & & \\
\hline Total & 1076 & 11 & 1.02 & & 460 & 12 & 2.6 & \\
\hline
\end{tabular}

$C L$, Confidence limits; DWI, deep wound infection; RITA, right internal thoracic artery. *In 19 patients, diabetes status could not be ascertained. 
TABLE 2. Incremental risk factors for deep sternal wound infection

\begin{tabular}{lrll}
\hline Factor & Coefficient \pm SE & $\boldsymbol{P}$ & Reliability (\%) \\
\hline RITA & & & \\
$\quad$ And diabetic & $1.0 \pm 0.5$ & .05 & - $^{*}$ \\
$\quad$ And nondiabetic & $-0.33 \pm 0.55$ & .5 & - $^{*}$ \\
No RITA & & & \\
$\quad$ And nondiabetic & $-0.73 \pm 0.48$ & .1 & -* $^{*}$ \\
Heavier weight & $0.79 \pm 0.22$ & .0003 & 66 \\
NYHA > class II & $0.8 \pm 0.38$ & .03 & 69 \\
Less severe stenosis of & $-1.27 \pm 0.60$ & .03 & 55 \\
$\quad$ LAD & & & \\
Propensity score & & & \\
RITA and diabetic & $-3.19 \pm 3.42$ & .4 & - $^{*}$ \\
RITA and nondiabetic & $0.38 \pm 1.80$ & .8 & - $^{*}$ \\
No RITA and nondiabetic & $-0.67 \pm 1.86$ & .7 & ${ }^{*}$ \\
\hline
\end{tabular}

$L A D$, Left anterior descending coronary artery; NYHA, New York Heart Association; RITA, right internal thoracic artery; $S E$, standard error. *Variables forced into model. $†$ Exp(weight/80).

and percentages. Confidence limits (CL) equivalent to 1 standard error $(68 \%)$ accompany outcomes.

\section{Results \\ DWI}

DWI occurred in $1.2 \%$ of patients (35/2,875, CL 1.0-1.4). Its occurrence was similar whether or not staged bilateral ITA grafting (RITA added) had been performed and whether or not the patient was diabetic (Table 1). In multivariable analysis, heavier patients were at increased risk of DWI $(P<.0003)$, as were those in higher New York Heart Association functional class $(P=.02)$, but not diabetics or patients undergoing staged bilateral ITA grafting (Table 2). Use of radial artery grafting likewise was not associated with increased risk of DWI.

\section{Hospital Mortality}

Hospital mortality was 4.6\% (132/2875, CL 4.2-5.0). It was higher in diabetics than nondiabetics in both unmatched (5.9\% vs $3.9 \%$ ) and propensity-matched (3.9\% vs $3.1 \%$ ) patients (Table 3). However, hospital mortality was lower and similar in diabetics and nondiabetics who underwent RITA grafting than in those who did not.

Nonuse of RITA at reoperation among diabetics was probably a risk factor for increased hospital mortality $(P=$ $.07)$, as was more extensive use of saphenous vein bypass grafts $(P=.001$, Table 4$)$. The most common graft was saphenous vein to left circumflex coronary artery (1678/ $2875,58 \%$ of patients) followed by saphenous vein to right coronary artery $(1621 / 2875,56 \%)$. RITA to left anterior descending coronary artery (LAD) was performed in $14 \%$ (405/2875), RITA to circumflex in $10 \%$ (288/2875), and saphenous vein to LAD in $20 \%$ (585/2875). A further 489 free ITA grafts were used for the LAD $(8.9 \%, \mathrm{n}=257)$ and left circumflex coronary artery $(8.1 \%, \mathrm{n}=232)$.

Other risk factors for hospital mortality included emergency surgery $(P<.0001)$, mitral valve replacement $(P<$ $.0001)$, and greater use of saphenous vein grafts $(P=.001$; see Table 4).

\section{Discussion}

This study shows that (1) staged use of bilateral ITAs does not increase risk of DWI, and (2) mortality did not increase and, indeed, may be lower for diabetics if RITA grafting is used. Clearly, anatomy of the coronary arteries must be suitable for this procedure and may have influenced outcome. Thus, the higher mortality risk with a greater number of venous bypasses likely reflects more complex and distal coronary artery disease requiring more bypasses.

It is interesting to speculate about why there was no increased risk of infection. Most likely, collateral blood

TABLE 3. Hospital mortality in nondiabetic and diabetic patients who did or did not receive right internal thoracic artery grafts at reoperation*

\begin{tabular}{|c|c|c|c|c|c|c|c|c|}
\hline \multirow{3}{*}{$\begin{array}{l}\text { RITA grafting } \\
\text { at reoperation }\end{array}$} & \multicolumn{4}{|c|}{ Nondiabetics } & \multicolumn{4}{|c|}{ Diabetics } \\
\hline & \multirow[b]{2}{*}{ n } & \multicolumn{3}{|c|}{ Hospital death } & \multirow[b]{2}{*}{$\mathbf{n}$} & \multicolumn{3}{|c|}{ Hospital death } \\
\hline & & No. & $\%$ & CL (\%) & & No. & $\%$ & CL (\%) \\
\hline \multicolumn{9}{|c|}{ Unmatched patients } \\
\hline Yes & 623 & 15 & 2.41 & $1.8-3.2$ & 271 & 4 & 1.48 & $0.8-2.6$ \\
\hline No & 1287 & 60 & 4.66 & $4.1-5.3$ & 675 & 52 & 7.70 & $6.7-8.9$ \\
\hline$P$ & .02 & \multicolumn{7}{|c|}{.0002} \\
\hline Total & 1910 & 75 & 3.93 & & 946 & 56 & 5.92 & \\
\hline \multicolumn{9}{|c|}{ Matched patients } \\
\hline Yes & 538 & 14 & 2.60 & $1.9-3.5$ & 230 & 4 & 1.74 & $0.9-3.1$ \\
\hline No & 538 & 19 & 3.53 & $2.7-4.5$ & 230 & 14 & 6.09 & $4.5-8.1$ \\
\hline$P$ & .4 & \multicolumn{7}{|c|}{.02} \\
\hline Total & 1076 & 33 & 3.1 & & 460 & 18 & 3.9 & \\
\hline
\end{tabular}

CL, Confidence limits; RITA, right internal thoracic artery. *In 19 patients, diabetes status could not be ascertained. 
TABLE 4. Multivariable analysis of hospital death

\begin{tabular}{lccc}
\hline Factor & Coefficient \pm SE & $\boldsymbol{P}$ & Reliability (\%) \\
\hline RITA & & & \\
$\quad$ And nondiabetic & $0.54 \pm 0.57$ & .3 & - $^{*}$ \\
No RITA & $0.96 \pm 0.54$ & .07 & - $^{*}$ \\
$\quad$ And diabetic & $0.54 \pm 0.54$ & .3 & - $^{*}$ \\
$\quad$ And nondiabetic & $1.76 \pm 0.32$ & $<.0001$ & 84 \\
Emergency operation & $1.27 \pm 0.29$ & $<.0001$ & 73 \\
$\begin{array}{l}\text { Concomitant mitral valve } \\
\quad \text { replacement }\end{array}$ & & & \\
$\begin{array}{l}\text { Total number of saphenous } \\
\quad \text { vein grafts }\end{array}$ & $0.27 \pm 0.08$ & .001 & 52 \\
$\begin{array}{l}\text { Propensity score } \\
\quad \text { No RITA and diabetic }\end{array}$ & $1.36 \pm 2.2$ & .5 & - $^{*}$ \\
$\quad \begin{array}{l}\text { No RITA and nondiabetic } \\
\text { RITA and nondiabetic }\end{array}$ & $0.78 \pm 1.79$ & .7 & - $^{*}$ \\
\hline
\end{tabular}

$R I T A$, Right internal thoracic artery; $S E$, standard error. *Variables forced into model.

flow developed to the left half of the sternum and manubrium from intercostal arteries after previous LITA harvesting. This collateral flow was sufficient to prevent ischemia, necrosis, and opportunity for seeded bacteria to grow after reoperation. ${ }^{24}$ This is in contrast to use of both ITAs at primary operation, for which risk of sternal and manubrial ischemia is increased because collateral flow from the intercostal arteries is more tenuous and poorly developed. ${ }^{5,9,10,14}$

Heavier weight has been shown to be a risk factor for DWI, ${ }^{5,6,9,11,12}$ as has diabetes. In this study, heavier weight was a risk factor even if the RITA was not used. , $6,9,11-14,18^{-10}$ Previous studies have shown that improved blood glucose control and skeletonized ITA pedicles may reduce this risk. $^{8,13,14,18}$

Risk factors for hospital mortality were similar to those previously reported, namely, emergency operation and mitral valve replacement. In 2003, hospital mortality for all coronary artery bypass reoperations at the Cleveland Clinic was $1.5 \%$ for 202 patients.

\section{Limitations}

This study represents a diverse group of patients. It is impossible to entirely adjust, by either multivariable analysis or propensity matching, for unmeasured variables and factors influencing surgeon selection of RITA grafting or for all factors associated with diabetes. Only a randomized study would more accurately delineate the influence of RITA grafting on risk of DWI, but based on improved hospital survival with RITA use, this is unlikely to be ethically justifiable.

We do not have long-term data on how staged LITA followed by RITA grafting influences late survival; however, previous publications by us and others have shown the benefits of LITA grafting and also bilateral grafting on long-term survival. $3,5,7,15,17,19$

\section{Conclusion}

RITA use for reoperations, including in diabetics, does not increase DWI risk and may improve hospital survival if the coronary anatomy is suitable.

We thank Tess Parry for editorial assistance and Gita Krishnaswamy and Penny Houghtaling for data checking.

\section{References}

1. Lytle BW, Blackstone EH, Loop FD, Houghtaling PL, Arnold JH, Akhrass R, et al. Two internal thoracic artery grafts are better than one. J Thorac Cardiovasc Surg. 1999;117:855-72.

2. Pick AW, Orszulak TA, Anderson BJ, Schaff HV. Single versus bilateral internal mammary artery grafts: 10-year outcome analysis. Ann Thorac Surg. 1997;64:599-605.

3. Galbut DL, Traad EA, Dorman MJ, DeWitt PL, Larsen PB, Kurlansky PA, et al. Coronary bypass grafting in the elderly. Single versus bilateral internal mammary artery grafts. $J$ Thorac Cardiovasc Surg. 1993;106:128-35 (discussion 35-6).

4. Zeitani J, Bertoldo F, Bassano C, Penta de Peppo A, Pellegrino A, El Fakhri FM, et al. Superficial wound dehiscence after median sternotomy: surgical treatment versus secondary wound healing. Ann Thorac Surg. 2004;77:672-5.

5. Loop FD, Lytle BW, Cosgrove DM, Mahfood S, McHenry MC, Goormastic M, et al. J. Maxwell Chamberlain memorial paper. Sternal wound complications after isolated coronary artery bypass grafting: early and late mortality, morbidity, and cost of care. Ann Thorac Surg. 1990;49:179-86 (discussion 86-7).

6. Uva MS, Braunberger E, Fisher M, Fromes Y, Deleuze PH, Celestin JA, et al. Does bilateral internal thoracic artery grafting increase surgical risk in diabetic patients? Ann Thorac Surg. 1998;66:2051-5.

7. Calafiore AM, Contini M, Vitolla G, Di Mauro M, Mazzei V, Teodori $\mathrm{G}$, et al. Bilateral internal thoracic artery grafting: long-term clinical and angiographic results of in situ versus Y grafts. $J$ Thorac Cardiovasc Surg. 2000;120:990-6.

8. Lytle BW. Skeletonized internal thoracic artery grafts and wound complications. J Thorac Cardiovasc Surg. 2001;121:625-7.

9. Abboud CS, Wey SB, Baltar VT. Risk factors for mediastinitis after cardiac surgery. Ann Thorac Surg. 2004;77:676-83.

10. Grossi EA, Esposito R, Harris LJ, Crooke GA, Galloway AC, Colvin $\mathrm{SB}$, et al. Sternal wound infections and use of internal mammary artery grafts. J Thorac Cardiovasc Surg. 1991;102:342-6 (discussion 6-7).

11. Engelman RM, Williams CD, Gouge TH, Chase RM, Jr., Falk EA, Boyd AD, et al. Mediastinitis following open-heart surgery. Review of two years' experience. Arch Surg. 1973;107:772-8.

12. Risk factors for deep sternal wound infection after sternotomy: a prospective, multicenter study. J Thorac Cardiovasc Surg. 1996;111: $1200-7$.

13. Furnary AP, Zerr KJ, Grunkemeier GL, Starr A. Continuous intravenous insulin infusion reduces the incidence of deep sternal wound infection in diabetic patients after cardiac surgical procedures. Ann Thorac Surg. 1999;67:352-60 (discussion 60-2).

14. Zerr KJ, Furnary AP, Grunkemeier GL, Bookin S, Kanhere V, Starr A Glucose control lowers the risk of wound infection in diabetics after open heart operations. Ann Thorac Surg. 1997;63:356-61.

15. Morris JJ, Smith LR, Jones RH, Glower DD, Morris PB, Muhlbaier $\mathrm{LH}$, et al. Influence of diabetes and mammary artery grafting on survival after coronary bypass. Circulation. 1991;84(suppl):III275-84.

16. Calafiore AM, Di Mauro M, Di Giammarco G, Contini M, Vitolla G, Iaco AL, et al. Effect of diabetes on early and late survival after isolated first coronary bypass surgery in multivessel disease. J Thorac Cardiovasc Surg. 2003;125:144-54.

17. Influence of diabetes on 5-year mortality and morbidity in a randomized trial comparing CABG and PTCA in patients with multivessel disease: the Bypass Angioplasty Revascularization Investigation (BARI). Circulation. 1997;96:1761-9.

18. Peterson MD, Borger MA, Rao V, Peniston CM, Feindel CM. Skeletonization of bilateral internal thoracic artery grafts lowers the risk of 
sternal infection in patients with diabetes. J Thorac Cardiovasc Surg. 2003;126:1314-9.

19. Loop FD, Lytle BW, Cosgrove DM, Stewart RW, Goormastic M, Williams GW, et al. Influence of the internal-mammary-artery graft on 10-year survival and other cardiac events. N Engl J Med. 1986; 314:1-6.

20. Rosenbaum PR, Rubin DB. The central role of the propensity score in observational studies for causal effects. Biometrika. 1983;70:41-55.
21. Blackstone EH. Comparing apples and oranges. J Thorac Cardiovasc Surg. 2002;123:8-15.

22. Breiman L. Bagging predictors. Machine Learning. 1996;24:123-40.

23. Drake C, Fisher L. Prognostic models and the propensity score. Int $J$ Epidemiol. 1995;24:183-7.

24. Lust RM, Sun YS, Chitwood WR, Jr. Internal mammary artery use. Sternal revascularization and experimental infection patterns. Circulation. 1991;84(suppl):III285-9. 